\title{
FIBRINOLYSIS PHENOTYPES DIFFER AMONGST CARDIAC SURGERY PATIENTS: ANTIFIBRINOLYTIC THERAPY FOR
}

\author{
ALL? \\ Matthew Sussman ${ }^{1}$, Eva Urrechaga ${ }^{1}$, Alessia Cioci $^{1}$, Rahul Iyengar ${ }^{1}$, Tyler Herrington ${ }^{1}$, \\ Emily Ryon ${ }^{1}$, Nick Namias ${ }^{1}$, david galbut ${ }^{1}$, Tomas Salerno ${ }^{2}$, and Kenneth Proctor ${ }^{1}$ \\ ${ }^{1}$ University of Miami Miller School of Medicine \\ ${ }^{2}$ university of miami miller school of medicine and jackson memorial hospital
}

August 28, 2020

\begin{abstract}
The recognition of fibrinolysis phenotypes in trauma patients has led to a reevaluation of antifibrinolytic therapy (AF). Many cardiac patients also receive AF, however the distribution of fibrinolytic phenotypes in that population is unknown. The purpose of this study was to fill that gap. Methods: Data were retrospectively reviewed from 78 cardiac surgery patients. Phenotypes were defined as hypofibrinolytic (LY30<0.8\%), physiologic (LY30 0.8-3.0\%) and hyperfibrinolytic (LY30>3\%). Continuous variables were expressed as $\mathrm{M} \pm \mathrm{SD}$ or median (interquartile range). Results: The study population was $65 \pm 10 \mathrm{yrs}$ old, $74 \%$ male, average body mass index of $29 \pm 5 \mathrm{~kg} / \mathrm{m} 2$. Fibrinolytic phenotypes were distributed as physiologic $=45 \%$, hypo $=32 \%$ and hyper $=23 \%$. There was no obvious effect of age, gender, race, or ethnicity on the distribution of fibrinolysis phenotypes; $47 \%$ received $\mathrm{AF}$. The time with chest tube during post-operative recovery was longer in those who received AF (4[3,5] days) vs no $\mathrm{AF}(3[2,4]$ days), $\mathrm{P}=0.037)$. All cause morbidity occurred in $51 \%$ of patients who received $\mathrm{AF}$ vs $25 \%$ with no $\mathrm{AF}$ ( $\mathrm{p}=0.017)$. However, with AF vs no AF, apparent differences in median chest tube output (1379 vs $820 \mathrm{ml}, \mathrm{p}=0.075)$, hospital LOS (13 vs 10 days, $\mathrm{P}=0.873$ ), estimated blood loss (1100 vs $775 \mathrm{ml}, \mathrm{P}=0.127)$, units of transfused $\mathrm{RBCs}(4$ vs 2 ], $\mathrm{P}=0.152)$ or all-cause mortality $(5.4 \%[2 / 37]$ vs $10 \%$ [4/41], $\mathrm{P}=0.518)$ were not statistically significant. Conclusion: This is the first description of three distinctly different fibrinolytic phenotypes in cardiac surgery patients. In this population, the use of AF was associated with increased morbidity.
\end{abstract}

\section{INTRODUCTION:}

Antifibrinolytics $(\mathrm{AF})$ reduce bleeding and need for blood product transfusion in complex cardiac surgery and cardio-pulmonary bypass (CPB) cases $^{1,2}$. The two most common AFs are Tranexamic acid (TXA) and Aminocaproic acid (ACA); both are lysine analogues that competitively inhibit conversion of plasminogen to plasmin ${ }^{3-5}$. AFs have demonstrated robust blood-loss reducing effects in a variety of settings without increased risk of thromboembolic events ${ }^{6}$. In 2011, The Society of Cardiovascular Anesthesiologists and Society of Thoracic Surgeons gave TXA their highest recommendation for use in blood conservation strategies although ACA is comparable in both efficacy and side effect profiles ${ }^{7}$. In the recent decade, use of AFs has expanded in both cardiac and non-cardiac surgery, with clinical applications in a wide range of surgical specialties $^{8}$.

The landmark CRASH-2 study concluded that early TXA reduced mortality in trauma patients ${ }^{9}$. Shortly thereafter, the MATTERs study reported similar benefits in the US military ${ }^{10}$. These compelling results led to an almost overnight paradigm shift and near worldwide incorporation of AF in trauma center resuscitation protocols, but questions soon followed. Why did less than half of the patients in CRASH-2 require PRBCs if they were bleeding to death? ${ }^{11}$ Why did only $5 \%$ of CRASH-2 patients die from hemorrhage ${ }^{11}$ ? CRASH-2 was 
also conducted in areas with underdeveloped rural trauma systems, leading to questions regarding application of CRASH-2 findings to mature urban trauma systems ${ }^{12}{ }^{13}$. Although TXA and ACA are generally welltolerated, deleterious effects include increased risk of seizure and increased mortality in certain high-risk subpopulations $^{14,15}$. Concern over these findings and persistent questions about the mechanism of action have resulted in variable integration of AFs in US trauma centers ${ }^{16-18}$.

Coagulopathy in cardiac and trauma surgery is diagnosed via a combination of conventional coagulation tests and viscoelastic assays such as the Thromboelastogram (TEG). TEG provides point-of-care evaluation of coagulation abnormalities and can guide coagulopathy treatment and decrease blood product use in cardiac surgery ${ }^{19-21}$.

The TEG LY30 value has been used to stratify distinct fibrinolytic phenotypes among trauma patients. The physiologic phenotype is defined as LY30 $=0.8-3.0 \%$ and is associated with the lowest mortality ${ }^{22}$. However, if TXA was administered to trauma patients who present to the hospital with physiologic levels of fibrinolysis, they had the highest mortality ${ }^{23}$. At the very least, this suggests that some patients may benefit from TXA more than others and that the mechanism may be associated with fibrinolysis ${ }^{24-28}$.

While there is some evidence regarding distribution and functional consequences of fibrinolytic phenotypes in trauma patients, no studies to date have investigated these ideas in cardiac surgery patients. The aim of this study was to fill that gap.

\section{METHODS:}

\section{Study Design}

All open cardiac surgery patients at a single academic institution in 2018 were retrospectively reviewed. Those who did not receive an intraoperative TEG or had incomplete TEG data were excluded. TEG was used to group patients according to fibrinolysis phenotypes. Otherwise, there were no exclusions based on age, medical co-morbidities, or other demographic information. The retrospective study was approved by the institutional review board with waiver of consent.

Demographic, clinical, and outcomes data were compared between groups. Demographic data included age, sex, race, ethnicity, insurance status, and medical comorbidities. Clinical variables included specific cardiac operation, total operative time, any intra-operative or post-operative surgical complications, and all peri-operative and post-operative medications. Outcomes of interest included estimated blood loss (EBL), post-operative length of stay (LOS), chest tube days, total chest tube output, number of packed red blood cells (pRBCs) transfused, all cause morbidity, and mortality (defined as disability and/or death from, cardiac arrest, cerebrovascular accident, congestive heart failure, hemothorax, multiorgan failure myocardial infarction, pleural effusion, respiratory failure, sepsis, thromboembolism, valve dysfunction, and/or wound dehiscence/abscess).

\section{Procedural and Statistical Analysis}

Each TEG was processed and analyzed by a Computerized Thrombelastograph Coagulation Analyzer (CTEG model 3000, Haemoscope Corporation, Skokie, Ill) in the hospital pathology lab. The TEG for each patient was performed using Celite-activated whole blood at $37^{\circ} \mathrm{C}$. The degree of fibrinolysis was defined by the LY30 value, which reflects the proportion of clot lysis 30 minutes after clot initiation. Three distinct fibrinolysis phenotypes were defined ${ }^{24-28} 1$ ) hypo-fibrinolytic (LY30<0.8\%), 2) physiologic fibrinolysis (LY30 0.8-3.0\%), and 3) hyper-fibrinolytic (LY30 >3\%).

Categorical variables are presented as counts (\%) and continuous variables as mean \pm standard deviation or median (interquartile range) based on the distribution of the corresponding variable. Outcomes of interest included hospital LOS, EBL, units of pRBCs, and all cause morbidity and mortality. Univariate analyses was performed using SPSS for Windows 6.0 (SPSS Corporation, Chicago, Ill) with significance assessed at $\mathrm{p}<0.05$.

\section{RESULTS}


A total of 117 cardiac surgery patients were reviewed between January 2018 and December 2018 but 39 were excluded because of incomplete TEG data. The final study population was comprised of 78 cardiac surgery patients and was characterized as 58 male $(74 \%)$ with a mean age of $65 \pm 10$ years (range, $44-87$ years). The mean body-mass-index (BMI) was $29 \pm 5$ (range $20-43) \mathrm{kg} / \mathrm{m}^{2}$. Patient race was categorized as $65 \%$ White $(\mathrm{n}$ $=51), 32 \%$ Black $(\mathrm{n}=25)$, and $3 \%$ Asian $(\mathrm{n}=2)$. The most common medical co-morbidity was hypertension (64\%) followed by coronary artery disease $(46 \%)$ and obesity $(35 \%)$ There was a near equal distribution of on-pump (48\%) and off-pump (51\%) cardiac surgery . Median LOS was 12 [8,17] days. Overall mortality was $8 \%$.

Fibrinolytic phenotypes were distributed as $45 \%$ physiologic, $32 \%$ hypo-, and $23 \%$ hyper-. There was no significant difference between age, gender, race, or ethnicity on the distribution of fibrinolysis phenotypes. There was a near equal distribution of fibrinolytic phenotypes between patients who received versus did not receive $\operatorname{AF}(\mathrm{P}=0.962)$.

Of the 78 patients included in the analysis, 47\% (37/78) received AF and 53\% (41/78) did not. When these two groups were further stratified by fibrinolytic phenotypes, the sub-group sizes were too small to make any meaningful determination of whether AF altered outcome .

Table 1 compares demographic and clinical data between groups. There were no statistically significant differences regarding: medical co-morbidities, including hypertension $(84 \%$ vs $71 \%, \mathrm{P}=0.172)$, coronary artery disease ( $57 \%$ vs $37 \%, \mathrm{P}=0.074)$, and diabetes $(35 \%$ vs $34 \%, \mathrm{P}=0.927)$, tobacco use $(3 \%$ vs $12 \%, \mathrm{P}$ $=0.116)$, preoperative hematocrit ( $34 \pm 3$ vs $33 \pm 4, \mathrm{P}=0.430)$, Caprini score $(9 \pm 2$ vs $9 \pm 2, \mathrm{P}=0.201)$ Clopidogrel use (19\% vs $24 \%, \mathrm{P}=0.559)$ or Aspirin use $(60 \%$ vs $78 \%, \mathrm{P}=0.076)$.

For AF versus no AF (Table 2), median time with chest tube during post-operative recovery was longer (4 $[3,5]$ vs $3[2,4]$ days, $\mathrm{p}=0.037)$. Chest tube output was increased $(1379[945,1837]$ vs $820[485,1400])$, but this apparent difference did not reach statistical significance $(\mathrm{P}=0.075)$. All-cause morbidity was the most significant outcome difference $(\mathrm{P}=.017)$, which occurred in $51 \%$ of patients who received AF versus $25 \%$ of patients who did not receive AF.

Other outcomes were similar, including hospital LOS $(13[8,17]$ vs $10[8,17]$ days, $\mathrm{P}=.873)$, EBL (1100 $[1000,1500]$ vs $775[500,1050] \mathrm{ml}, \mathrm{P}=.127)$, transfused RBCs $(4[1,5]$ vs $2[1,4]$ units, $\mathrm{P}=.152)$ or all-cause mortality $(5.4 \%$ vs $10 \%, \mathrm{P}=.518)$.

\section{DISCUSSION}

Fibrinolysis is a physiologic mechanism by which clots are degraded to maintain the patency of microvasculature. Pathologic over- or under-activation of fibrinolysis has significant clinical implications regarding optimal treatment interventions and patient outcomes in trauma patients ${ }^{22-28}$. This study is the first to categorize these fibrinolysis phenotypes in cardiac surgery patients. The data suggest that indiscriminate AF administration may have deleterious effects unless clinically indicated, but the sample size is too small to make definitive recommendations.

Hyper-, physiologic, and hypo-fibrinolytic phenotypes are well established among trauma patients. In theory, $\mathrm{AF}$ should have its most favorable effect in those with hyperfibrinolysis. In contrast, hypercoagulability associated with fibrinolytic shutdown is reported to occur in $46 \%$ to over $64 \%$ of trauma patients ${ }^{22-32}$. On this basis alone, it is reasonable to propose that all patients likely do not benefit from TXA ${ }^{11}$. Despite the high prevalence, it remains controversial if fibrinolytic shutdown is a physiological or maladaptive response to traumatic injury ${ }^{33,34}$. Our study demonstrates a distribution of fibrinolytic phenotypes in cardiac surgery patients that is distinctly different than the established distributions among trauma patients. In particular, our data shows that cardiac surgery patients exhibited a rate of fibrinolytic shutdown of $32 \%$ compared to the reported range for trauma patients of $46-64 \%$.

There are multiple proposed mechanisms by which fibrinolytic shutdown occurs, including: i) tissue plasminogen activator (t-PA) inhibition, ii) inadequate t-PA release in response to injury, iii) fibrinolytic resistance via

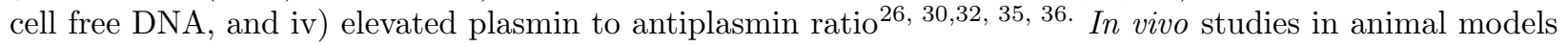


have demonstrated that tPA release is predominantly driven by shock rather than by tissue injury and that altered clot formation has no correlation with altered clot degradation ${ }^{22,36,37}$. Subsequent studies have yet to identify a correlation between injury severity score or injury mechanism and fibrinolytic phenotype ${ }^{36,} 38$. Nevertheless, changes in the fibrinolytic system after tissue injury have significant treatment implications regarding the treatment decision to administer or withhold AF therapy.

Although distinct fibrinolytic phenotypes are well-established in trauma patients, equivalent phenotypes are yet to be fully characterized in other surgical fields. Many studies have investigated the efficacy of empiric AF treatment across surgical groups; however, there is limited discussion of the prevalence or influence of distinct fibrinolytic phenotypes on treatment responsiveness and outcomes. In particular, there may be an increased potential for preventable harm if $\mathrm{AF}$ is administered to a patient who is already hypofibrinolytic (i.e. fibrinolysis shutdown=hypercoagulable), or if withheld from a patient who is hyperfibrinolytic (i.e. hypocoagulable).

In the United States, patients undergoing cardiac surgery demonstrate particularly high blood transfusion rates. In 2010, $34 \%$ of cardiac surgery patients received a perioperative transfusion despite the implementation of blood conservation guidelines in $2007^{39-41}$. Thus, AF is often used in this population to minimize perioperative blood loss ${ }^{42}$. It is well established that AF therapy reduces bleeding and allogeneic transfusion requirements ${ }^{29}$. Myles et al studied the effectiveness of TXA versus placebo in a randomized control study of 4631 coronary-artery surgical patients and demonstrated that death or thrombotic complication occurred in $18.1 \%$ of placebo patients versus $16.7 \%$ of TXA patients ${ }^{43}$. Transfusion requirements were reduced from 7,994 total units in placebo to 4,331 in the TXA group, with seizures reported in $0.1 \%$ of placebo versus $0.7 \%$ of TXA patients ${ }^{43}$. A recent metanalysis by Alaifan et al reported that TXA reduced bleeding in cardiac surgery, but surprisingly did not significantly impact overall mortality ${ }^{49}$. A randomized control trial by Leff at el comparing TXA and ACA in 114 cardiac surgery patients demonstrated that ACA was associated with less transfusions than TXA; though, both TXA and ACA significantly reduced perioperative bleeding and transfusions with no increase in adverse events ${ }^{45}$. The efficacy of AF in reducing perioperative bleeding and transfusion requirements has been reported by several others ${ }^{46-48}$.

Our data demonstrated significant outcome differences in those who received AF versus those who did not. We show that cardiac surgery patients who received AF had significantly higher rate of all cause morbidity $(\mathrm{n}=19,51 \%)$ versus those who did not $(\mathrm{n}=10,25 \%, \mathrm{P}=0.017)$. Patients who received AF also had more days with a chest tube $(\mathrm{P}=0.037)$ and an average of $559 \mathrm{~mL}$ more output from the chest tube compared to patients who did not receive TXA $(\mathrm{P}=0.075)$. Unfortunately, the sample size was not large enough to determine if these outcome differences were related to the fibrinolytic phenotype.

There was no obvious effect of age, gender, race, or ethnicity on the distribution of fibrinolysis phenotypes. There was a near equal distribution of physiologic, hyper-, and hypo-fibrinolytic phenotypes between patients who received $\mathrm{AF}$ ( $46 \%$ vs $30 \%$ vs $24 \%$ ) and did not receive $\mathrm{AF}$ ( $45 \%$ vs $33 \%$ vs $22 \%, \mathrm{P}=0.962$ ). This suggests that a patient's fibrinolytic phenotype was not a contributing factor in the decision to administer or withhold $\mathrm{AF}$.

The use of AF in other surgical populations has generally been efficacious; though, there is significant heterogeneity across specialties. For instance, patients with hepatic dysfunction are at a markedly increased risk of excessive bleeding or coagulopathy during liver surgery or transplantation due to altered hepatic production of essential clotting factors ${ }^{49}$. Previously, AF were administered empirically in these patients; however, empiric therapy has since been questioned due an observed increase in rates of coagulopathy, venous thromboembolism, and mortality ${ }^{49-51}$. In current practice, the use of AF during hepatic operations is variable due to the considerable physiologic changes that occur pre- and post-liver transplantation. Accordingly, most liver transplant centers use TEG or viscoelastic monitoring with rotational thromboelastometry to guide AF administration if a patient exhibits hyperfibrinolysis ${ }^{52-54}$. Similarly, it has been established that only some trauma patients benefit from empiric AF therapy. Thus, the use of AF in trauma is generally informed and guided by TEG or comparable monitoring techniques. 
The practical significance of fibrinolytic phenotype and therapeutic response has only recently been recognized. Even among the fields of liver and trauma surgery, where fibrinolytic variability has been consistently reported, there is still limited discussion of the relationship between AF and clinical outcomes across distinct fibrinolytic phenotypes.

Ultimately, further investigation is needed to assess the role of fibrinolytic phenotypes in modulating AF responsiveness and clinical outcomes, especially because AF therapy has a demonstrated utility in cardiac surgery. Ultimately, TEG -guided AF therapy might assure administration only when clinically indicated..

Our study is limited by its small sample size and retrospective methodology, which precluded subgroup analysis of AF outcomes across fibrinolytic phenotypes. Our small study size also hindered statistical significance of some outcome variables; though, we still observed clinically significant differences among patients who received AF, including an average of 325mL more EBL $(\mathrm{P}=0.127)$ and 2 units more of RBCs transfused (P $=0.152$ ) compared to patients who did not receive AF. Considering that fibrinolytic phenotypes and most demographic factors were relatively equal between patients who did and did not receive AF, these observed differences following AF may suggest a contributory role of fibrinolytic phenotype on patient outcomes. Therefore, a better understanding of fibrinolytic phenotypes may be especially significant in guiding the decision to administer or withhold AF in surgical patients.

In summary, this study is the first to describe three distinct fibrinolytic phenotypes in cardiac surgery patients. This distribution is different than the established distribution of fibrinolytic phenotypes in trauma patients. In most surgical specialties, intra-operative AF safely and effectively reduces bleeding complications, but there is on strong evidence from trauma patients that fibrinolytic phenotypes in modulating treatment responses to AF. In context with these current findings, we hope to open the dialog on whether it is safe to administer AFs to cardiac surgery patients who are normo- or hypofibrinolytic. Further studies are clearly indicated in cardiac surgery patients to investigate the clinical utility of pre- and post-operative TEG data to discern fibrinolytic phenotypes and guide AF use.

\section{AUTHOR CONTRIBUTIONS:}

MSS and ELR had full access to all the data and take responsibility for the accuracy of the analysis.

Study concept and design: MSS, TAS, DLG, KGP

Acquisition, analysis, or interpretation of data: MSS, TH, RI

Drafting of the manuscript: MSS, RI, TH, EMU, ACC, KGP

Critical revision of the manuscript for important intellectual content: All authors

Statistical analysis: MSS, ELR

Administrative, technical, or material support: NN, TAS

Study supervision: KGP

\section{ACKNOWLEDGMENTS:}

We appreciate the efforts of Ronald J. Manning, RN, BSN, APRN, MSPH, for coordinating all clinical research activities and maintain compliance documentation and medical students Rajan Ramdev, BS, Hogan Brecount, BS, Stephen P. Wittels, BS, who helped with patient identification and data acquisition.

\section{REFERENCES}

1. Brown RS, Thwaites BK, Mongan PD. Tranexamic acid is effective in decreasing postoperative bleeding and transfusions in primary coronary artery bypass operations: a double-blind, randomized, placebocontrolled trial. Anesth Analg. 1997 Nov;85(5):963-70. PMID: 9356085. 
2. Fremes SE, Wong BI, Lee E, Mai R, Christakis GT, McLean RF, Goldman BS, Naylor CD. Metaanalysis of prophylactic drug treatment in the prevention of postoperative bleeding. Ann Thorac Surg. 1994 Dec;58(6):1580-8. PMID: 7526811.

3. Fergusson DA, Hébert PC, Mazer CD, Fremes S, MacAdams C, Murkin JM, Teoh K, Duke PC, Arellano R, Blajchman MA, Bussières JS, Côté D, Karski J, Martineau R, Robblee JA, Rodger M, Wells G, Clinch J, Pretorius R; BART Investigators. A comparison of aprotinin and lysine analogues in high-risk cardiac surgery. N Engl J Med. 2008 May 29;358(22):2319-31. Erratum in: N Engl J Med. 2010 Sep 23;363(13):1290. PMID: 18480196..

4. Koster A, Faraoni D, Levy JH. Antifibrinolytic Therapy for Cardiac Surgery: An Update. Anesthesiology. 2015 Jul;123(1):214-21. PMID: 25950230..

5. Gerstein NS, Brierley JK, Windsor J, Panikkath PV, Ram H, Gelfenbeyn KM, Jinkins LJ, Nguyen LC, Gerstein WH. Antifibrinolytic Agents in Cardiac and Noncardiac Surgery: A Comprehensive Overview and Update. J Cardiothorac Vasc Anesth. 2017 Dec;31(6):2183-2205. PMID: 28457777

6. Ker K, Edwards P, Perel P, Shakur H, Roberts I. Effect of tranexamic acid on surgical bleeding: systematic review and cumulative meta-analysis. BMJ. 2012 May 17;344:e3054. PMID: 22611164;

7. Society of Thoracic Surgeons Blood Conservation Guideline Task Force, Ferraris VA, Brown JR, Despotis GJ, Hammon JW, Reece TB, Saha SP, Song HK, Clough ER; Society of Cardiovascular Anesthesiologists Special Task Force on Blood Transfusion, Shore-Lesserson LJ, Goodnough LT, Mazer CD, Shander A, Stafford-Smith M, Waters J; International Consortium for Evidence Based Perfusion, Baker RA, Dickinson TA, FitzGerald DJ, Likosky DS, Shann KG. 2011 update to the Society of Thoracic Surgeons and the Society of Cardiovascular Anesthesiologists blood conservation clinical practice guidelines. Ann Thorac Surg. 2011 Mar;91(3):944-82. PMID: 21353044.

8. Tengborn L, Blombäck M, Berntorp E. Tranexamic acid-an old drug still going strong and making a revival. Thromb Res. 2015 Feb;135(2):231-42. PMID: 25559460.

9. CRASH-2 trial collaborators, Shakur H, Roberts I, Bautista R, Caballero J, Coats T, Dewan Y, El-Sayed H, Gogichaishvili T, Gupta S, Herrera J, Hunt B, Iribhogbe P, Izurieta M, Khamis H, Komolafe E, Marrero MA, Mejía-Mantilla J, Miranda J, Morales C, Olaomi O, Olldashi F, Perel P, Peto R, Ramana PV, Ravi RR, Yutthakasemsunt S. Effects of tranexamic acid on death, vascular occlusive events, and blood transfusion in trauma patients with significant haemorrhage (CRASH-2): a randomised, placebo-controlled trial. Lancet. 2010 Jul 3;376(9734):23-32. PMID: 20554319.

10. Morrison JJ, Dubose JJ, Rasmussen TE, Midwinter MJ. Military Application of Tranexamic Acid in Trauma Emergency Resuscitation (MATTERs) Study. Arch Surg. 2012 Feb;147(2):113-9. PMID: 22006852.

11. Valle EJ, Allen CJ, Van Haren RM, Jouria JM, Li H, Livingstone AS, Namias N, Schulman CI, Proctor KG. Do all trauma patients benefit from tranexamic acid? J Trauma Acute Care Surg. 2014 Jun;76(6):1373-8. PMID: 24854303

12. Binz S, McCollester J, Thomas S, Miller J, Pohlman T, Waxman D, Shariff F, Tracy R, Walsh M. CRASH2 Study of Tranexamic Acid to Treat Bleeding in Trauma Patients: A Controversy Fueled by Science and Social Media. J Blood Transfus. 2015;2015:874920. PMID: 26448897;

13. Peden M, McGee K, Sharma G. The injury chart book: a graphical overview of the global bu. rden of injuries. Geneva, World Health Organization, 2002 ISBN 924156220 X (NLM classification: WO 700)

14. Lin Z, Xiaoyi Z. Tranexamic acid-associated seizures: A meta-analysis. Seizure. 2016 Mar;36:70-73. PMID: 26967164.

15. Kaseer H, Sanghavi D. Aminocaproic Acid. [Updated 2020 Feb 26]. In: StatPearls [Internet]. Treasure Island (FL): StatPearls Publishing; 2020 Jan-. Available from: https://www.ncbi.nlm.nih.gov/books/NBK554475/ 
16. Napolitano LM, Cohen MJ, Cotton BA, Schreiber MA, Moore EE. Tranexamic acid in trauma: how should we use it? J Trauma Acute Care Surg. 2013 Jun;74(6):1575-86. PMID: 23694890.

17. Pusateri AE, Weiskopf RB, Bebarta V, Butler F, Cestero RF, Chaudry IH, Deal V, Dorlac WC, Gerhardt RT, Given MB, Hansen DR, Hoots WK, Klein HG, Macdonald VW, Mattox KL, Michael RA, Mogford J, Montcalm-Smith EA, Niemeyer DM, Prusaczyk WK, Rappold JF, Rassmussen T, Rentas F, Ross J, Thompson C, Tucker LD; US DoD Hemorrhage and Resuscitation Research and Development Steering Committee. Tranexamic acid and trauma: current status and knowledge gaps with recommended research priorities. Shock. 2013 Feb;39(2):121-6. PMID: 23222525.

18. Cole E, Davenport R, Willett K, Brohi K. Tranexamic acid use in severely injured civilian patients and the effects on outcomes: a prospective cohort study. Ann Surg. 2015 Feb;261(2):390-4. PMID: 25412319.

19. Yeung MC, Tong SY, Tong PY, Cheung BH, Ng JY, Leung GK. Use of viscoelastic haemostatic assay in emergency and elective surgery. Hong Kong Med J. 2015 Feb;21(1):45-51. PMID: 25082123

20. Kaufmann CR, Dwyer KM, Crews JD, Dols SJ, Trask AL. Usefulness of thrombelastography in assessment of trauma patient coagulation. J Trauma. 1997 Apr;42(4):716-20; discussion 720-2. PMID: 9137263.

21. Ak K, Isbir CS, Tetik S, Atalan N, Tekeli A, Aljodi M, Civelek A, Arsan S. Thromboelastography-based transfusion algorithm reduces blood product use after elective CABG: a prospective randomized study. J Card Surg. 2009 Jul-Aug;24(4):404-10. PMID: 19583608.

22. Moore HB, Moore EE, Gonzalez E, Chapman MP, Chin TL, Silliman CC, Banerjee A, Sauaia A. Hyperfibrinolysis, physiologic fibrinolysis, and fibrinolysis shutdown: the spectrum of postinjury fibrinolysis and relevance to antifibrinolytic therapy. J Trauma Acute Care Surg. 2014 Dec;77(6):811-7; discussion 817. PMID: 25051384;

23. Moore HB, Moore EE, Huebner BR, Stettler GR, Nunns GR, Einersen PM, Silliman CC, Sauaia A. Tranexamic acid is associated with increased mortality in patients with physiological fibrinolysis. J Surg Res. 2017 Dec;220:438-443. PMID: 28755903;

24. Moore EE, Moore HB, Gonzalez E, Chapman MP, Hansen KC, Sauaia A, Silliman CC, Banerjee A. Postinjury fibrinolysis shutdown: Rationale for selective tranexamic acid. J Trauma Acute Care Surg. 2015 Jun;78(6 Suppl 1):S65-9. PMID: 26002266;.

25. Moore HB, Moore EE, Liras IN, Gonzalez E, Harvin JA, Holcomb JB, Sauaia A, Cotton BA. Acute Fibrinolysis Shutdown after Injury Occurs Frequently and Increases Mortality: A Multicenter Evaluation of 2,540 Severely Injured Patients. J Am Coll Surg. 2016 Apr;222(4):347-55. PMID: 26920989

26. Moore HB, Moore EE, Huebner BR, Dzieciatkowska M, Stettler GR, Nunns GR, Lawson PJ, Ghasabyan A, Chandler J, Banerjee A, Silliman C, Sauaia A, Hansen KC. Fibrinolysis shutdown is associated with a fivefold increase in mortality in trauma patients lacking hypersensitivity to tissue plasminogen activator. J Trauma Acute Care Surg. 2017 Dec;83(6):1014-1022. PMID: 29190254

27. Meizoso JP, Karcutskie CA, Ray JJ, Namias N, Schulman CI, Proctor KG. Persistent Fibrinolysis Shutdown Is Associated with Increased Mortality in Severely Injured Trauma Patients. J Am Coll Surg. 2017 Apr;224(4):575-582. PMID: 28017804

28. Leeper CM, Strotmeyer SJ, Neal MD, Gaines BA. Window of Opportunity to Mitigate Trauma-induced Coagulopathy: Fibrinolysis Shutdown not Prevalent Until 1 Hour Post-injury. Ann Surg. 2019 Sep;270(3):528534. PMID: 31305285

29. Levy JH, Koster A, Quinones QJ, Milling TJ, Key NS. Antifibrinolytic Therapy and Perioperative Considerations. Anesthesiology. 2018 Mar;128(3):657-670. PMID: 29200009;

30. Raza I, Davenport R, Rourke C, Platton S, Manson J, Spoors C, Khan S, De'Ath HD, Allard S, Hart DP, Pasi KJ, Hunt BJ, Stanworth S, MacCallum PK, Brohi K. The incidence and magnitude of fibrinolytic 
activation in trauma patients. J Thromb Haemost. 2013 Feb;11(2):307-14.. PMID: 23176206

31. Madurska MJ, Sachse KA, Jansen JO, Rasmussen TE, Morrison JJ. Fibrinolysis in trauma: a review. Eur J Trauma Emerg Surg. 2018 Feb;44(1):35-44. PMID: 28918481

32. Cardenas JC, Wade CE, Cotton BA, George MJ, Holcomb JB, Schreiber MA, White NJ; PROPPR Study Group. TEG Lysis Shutdown Represents Coagulopathy in Bleeding Trauma Patients: Analysis of the PROPPR Cohort. Shock. 2019 Mar;51(3):273-283. PMID: 2966 836;

33. Gomez-Builes JC, Acuna SA, Nascimento B, Madotto F, Rizoli SB. Harmful or Physiologic: Diagnosing Fibrinolysis Shutdown in a Trauma Cohort With Rotational Thromboelastometry. Anesth Analg. 2018 Oct;127(4):840-849. PMID: 29683829

34. Veigas PV, Callum J, Rizoli S, Nascimento B, da Luz LT. A systematic review on the rotational thrombelastometry (ROTEM $囚$ ) values for the diagnosis of coagulopathy, prediction and guidance of blood transfusion and prediction of mortality in trauma patients. Scand J Trauma Resusc Emerg Med. 2016 Oct 3;24(1):114. PMID: 27716278

35. Gould TJ, Vu TT, Stafford AR, Dwivedi DJ, Kim PY, Fox-Robichaud AE, Weitz JI, Liaw PC. Cell-Free DNA Modulates Clot Structure and Impairs Fibrinolysis in Sepsis. Arterioscler Thromb Vasc Biol. 2015 Dec;35(12):2544-53. PMID: 26494232

36. Moore HB, Moore EE, Lawson PJ, Gonzalez E, Fragoso M, Morton AP, Gamboni F, Chapman MP, Sauaia A, Banerjee A, Silliman CC. Fibrinolysis shutdown phenotype masks changes in rodent coagulation in tissue injury versus hemorrhagic shock. Surgery. 2015 Aug;158(2):386-92. PMID: 25979440;

37. Chin TL, Moore EE, Moore HB, Gonzalez E, Chapman MP, Stringham JR, Ramos CR, Banerjee A, Sauaia A. A principal component analysis of postinjury viscoelastic assays: clotting factor depletion versus fibrinolysis. Surgery. 2014 Sep;156(3):570-7. PMID: 24962188;

38. Lee TH, Hampton DA, Diggs BS, McCully SP, Kutcher M, Redick BJ, Podbielski J, Cotton BA, Cohen M, Schreiber MA. Traumatic brain injury is not associated with coagulopathy out of proportion to injury in other body regions. J Trauma Acute Care Surg. 2014 Jul;77(1):67-72; discussion 72. PMID: 24977757

39. Robich MP, Koch CG, Johnston DR, Schiltz N, Chandran Pillai A, Hussain ST, Soltesz EG. Trends in blood utilization in United States cardiac surgical patients. Transfusion. 2015 Apr;55(4):805-14. PMID: 25363570

40. Goel R, Patel EU, White JL, Chappidi MR, Ness PM, Cushing MM, Takemoto CM, Shaz BH, Frank SM, Tobian AAR. Factors associated with red blood cell, platelet, and plasma transfusions among inpatient hospitalizations: a nationally representative study in the United States. Transfusion. 2019 Feb;59(2):500-507. PMID: 30548491

41. Arias-Morales CE, Stoicea N, Gonzalez-Zacarias AA, Slawski D, Bhandary SP, Saranteas T, Kaminiotis E, Papadimos TJ. Revisiting blood transfusion and predictors of outcome in cardiac surgery patients: a concise perspective. F1000Res. 2017 Feb 20;6:F1000 Faculty Rev-168. PMID: 28299184

42. Petrou A, Tzimas P, Siminelakis S. Massive bleeding in cardiac surgery. Definitions, predictors and challenges. Hippokratia. 2016 Jul-Sep;20(3):179-186. PMID: 29097882;.

43. Myles PS, Smith JA, Forbes A, Silbert B, Jayarajah M, Painter T, Cooper DJ, Marasco S, McNeil J, Bussières JS, McGuinness S, Byrne K, Chan MT, Landoni G, Wallace S; ATACAS Investigators of the ANZCA Clinical Trials Network. Tranexamic Acid in Patients Undergoing Coronary-Artery Surgery. N Engl J Med. 2017 Jan 12;376(2):136-148. Erratum in: N Engl J Med. 2018 Feb 22;378(8):782. PMID: 27774838.

44. Alaifan T, Alenazy A, Xiang Wang D, Fernando SM, Spence J, Belley-Cote E, Fox-Robichaud A, Ainswoth C, Karachi T, Kyeremanteng K, Zarychanski R, Whitlock R, Rochwerg B. Tranexamic acid in cardiac 
surgery: a systematic review and meta- analysis (protocol). BMJ Open. 2019 Sep 17;9(9):e028585. PMID: 31530593 ;

45. Leff J, Rhee A, Nair S, Lazar D, Sathyanarayana SK, Shore-Lesserson L. A randomized, double-blinded trial comparing the effectiveness of tranexamic acid and epsilon-aminocaproic acid in reducing bleeding and transfusion in cardiac surgery. Ann Card Anaesth. 2019 Jul-Sep;22(3):265-272. PMID: 31274487;

46. Karski JM, Teasdale SJ, Norman PH, Carroll JA, Weisel RD, Glynn MF. Prevention of postbypass bleeding with tranexamic acid and epsilon-aminocaproic acid. J Cardiothorac Vasc Anesth. 1993 Aug;7(4):431-5. PMID: 8104526

47. O, Aqil A, Asmar S, Vanker R, Hahnel J, Brew C, Grogan R, Radcliffe G. Epsilon-aminocaproic acid versus tranexamic acid in total knee arthroplasty: a meta-analysis study. J Orthop Traumatol. 2019 Jul 18;20(1):28. PMID: 31321578;

48. Lu J, Meng H, Meng Z, Sun Y, Pribis JP, Zhu C, Li Q. Epsilon aminocaproic acid reduces blood transfusion and improves the coagulation test after pediatric open-heart surgery: a meta-analysis of 5 clinical trials. Int J Clin Exp Pathol. 2015 Jul 1;8(7):7978-87. PMID: 26339364

49. Roullet S, Pillot J, Freyburger G, Biais M, Quinart A, Rault A, Revel P, Sztark F. Rotation thromboelastometry detects thrombocytopenia and hypofibrinogenaemia during orthotopic liver transplantation. $\mathrm{Br}$ J Anaesth. 2010 Apr;104(4):422-8. PMID: 20185519

50. Porte RJ, Molenaar IQ, Begliomini B, Groenland TH, Januszkiewicz A, Lindgren L, Palareti G, Hermans J, Terpstra OT. Aprotinin and transfusion requirements in orthotopic liver transplantation: a multicentre randomised double-blind study. EMSALT Study Group. Lancet. 2000 Apr 15;355(9212):1303-9. PMID: 10776742

51. Dalmau A, Sabaté A, Acosta F, Garcia-Huete L, Koo M, Sansano T, Rafecas A, Figueras J, Jaurrieta E, Parrilla P. Tranexamic acid reduces red cell transfusion better than epsilon-aminocaproic acid or placebo in liver transplantation. Anesth Analg. 2000 Jul;91(1):29-34. PMID: 10866882

52. da Luz LT, Nascimento B, Rizoli S. Thrombelastography (TEG@): practical considerations on its clinical use in trauma resuscitation. Scand J Trauma Resusc Emerg Med. 2013 Apr 16;21:29. doi: 10.1186/1757-724121-29. PMID: 23587157

53. Kutcher ME, Ferguson AR, Cohen MJ. A principal component analysis of coagulation after trauma. J Trauma Acute Care Surg. 2013 May;74(5):1223-9; discussion 1229-30. PMID: 23609271

54. Molenaar IQ, Warnaar N, Groen H, Tenvergert EM, Slooff MJ, Porte RJ. Efficacy and safety of antifibrinolytic drugs in liver transplantation: a systematic review and meta-analysis. Am J Transplant. 2007 Jan;7(1):185-94. PMID: 17227567

\begin{tabular}{llllllll}
\hline $\begin{array}{l}N(\%), \\
\text { mean } \pm S D\end{array}$ & $\begin{array}{l}N(\%), \\
\text { mean } \pm S D\end{array}$ & $\begin{array}{l}\text { No } A F \\
(n=41)\end{array}$ & $\begin{array}{l}\text { No } A F \\
(n=41)\end{array}$ & $A F(n=37)$ & $A F(n=37)$ & $P$-value & P-value \\
\hline $\begin{array}{l}\text { Age } \\
\text { (years) }\end{array}$ & & & $63 \pm 10$ & $63 \pm 10$ & $67 \pm 10$ & $67 \pm 10$ & 0.090 \\
Gender & Male & Male & $29(71)$ & $29(71)$ & $29(78)$ & $29(78)$ & 0.440 \\
& Female & Female & $12(29)$ & $12(29)$ & $8(22)$ & $8(22)$ & \\
Race & White & White & $29(71)$ & $29(71)$ & $22(60)$ & $22(60)$ & 0.246 \\
& Black & Black & $12(29)$ & $12(29)$ & $13(35)$ & $13(35)$ & \\
& Asian & Asian & $0(0)$ & $0(0)$ & $2(5)$ & $2(5)$ & 0.172 \\
Hypertention & & & $29(71)$ & $29(71)$ & $31(84)$ & $31(84)$ & 0.074 \\
CAD & & & $15(37)$ & $15(37)$ & $21(57)$ & $21(57)$ & 0.927
\end{tabular}




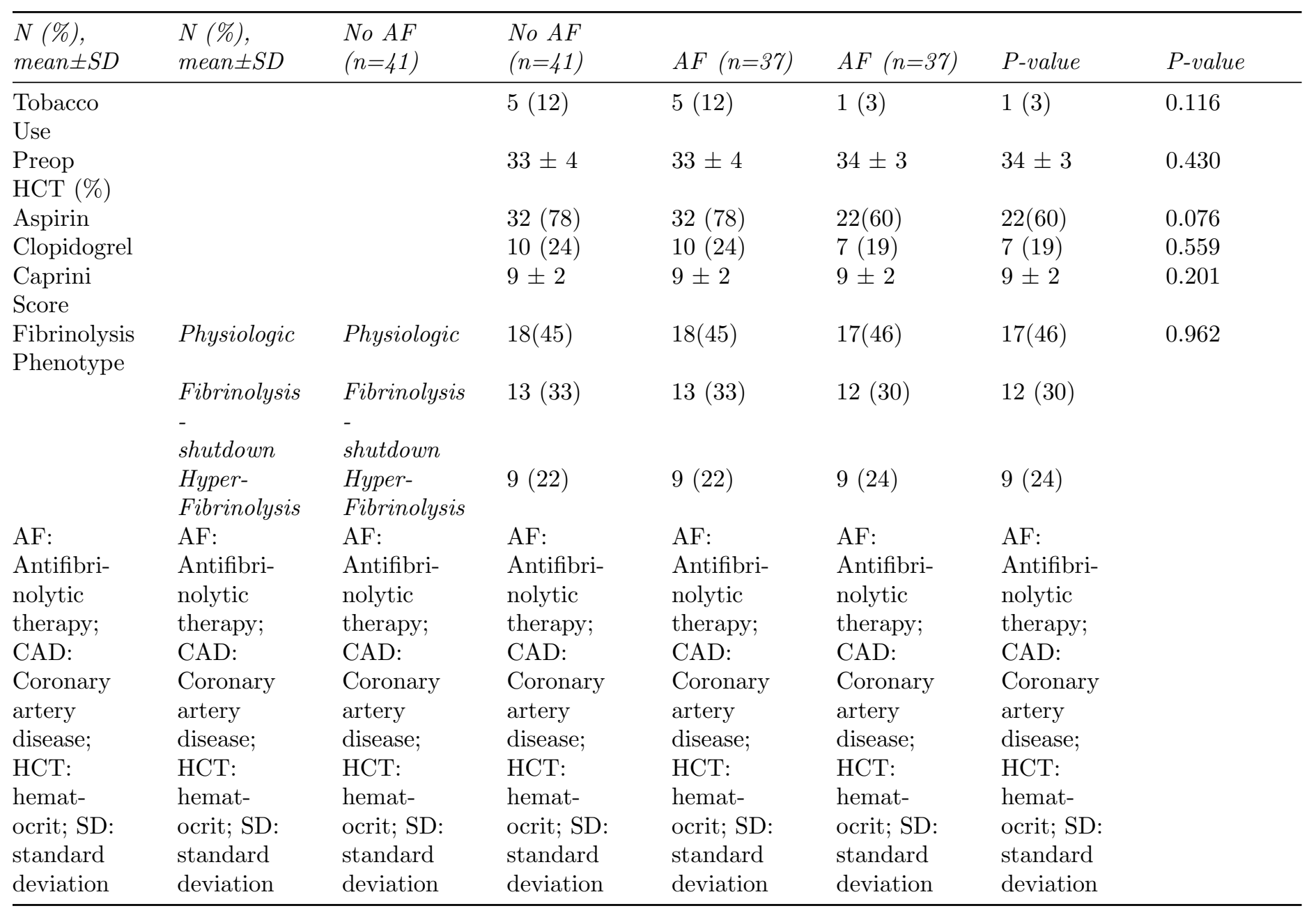

Table 1

Table 2

\begin{tabular}{ll}
\hline Antifibrinolytic Therapy Outcomes & Antifibrinolytic Thera \\
\hline$N(\%)$, median [IQR] & No AF \\
Hospital LOS (Days) & $10[8,17]$ \\
Chest Tube Days (Days) & $3[2,4]$ \\
Chest Tube Output (mL) & $820[485,1400]$ \\
EBL (mL) & $775[500,1050]$ \\
RBC Transfused (units) & $2[1,4]$ \\
All Cause Mortality & $4(10)$ \\
All Cause Morbidity & $10(25)$ \\
AF: Antifibrinolytic therapy; EBL: estimated blood loss; LOS: length of stay: RBC: red blood cells & AF: Antifibrinolytic t \\
\hline
\end{tabular}

